\title{
Superação da dormência em sementes de Bromelia balansae (Bromeliaceae)
}

\author{
Maria de Fátima B Coelho ${ }^{1}$; Sandro N Vieira²; Leo A Chig²; Laercio W Santos ${ }^{1}$; Maria Cristina de F e \\ Albuquerque ${ }^{2}$ \\ ${ }^{1}$ UFERSA, C. Postal 137, 59625-900 Mossoró-RN; coelhomfstrela@gmail.com; laerwan@gmail.com; ${ }^{2}$ UFMT, Av. Fernando Correa da \\ Costa s/n, 78060-900 Cuiabá-MT; sandronunesvieira@yahoo.com.br; leochig@gmail.com; mariacfa@terra.com.br
}

\begin{abstract}
RESUMO
Os efeitos da temperatura, substratos e tratamentos pré-germinativos para a superação da dormência foram avaliados na germinação de sementes de Bromelia balansae (caraguatá) oriundas de frutos coletados em Chapada dos Guimarães-MT. O delineamento experimental foi inteiramente casualizado com cinco repetições de 50 sementes por parcela. No primeiro experimento as sementes foram submetidas a seis tratamentos: a) $25^{\circ} \mathrm{C}$ e sobre papel, b) $30^{\circ} \mathrm{C}$ e entre papel, c) $25^{\circ} \mathrm{C}$ sobre papel, d) $30^{\circ} \mathrm{C}$ e entre papel, e) alternada $25 / 30^{\circ} \mathrm{C}$ e sobre papel e f) alternada $25 / 30^{\circ} \mathrm{C}$ e entre papel. No segundo foram avaliados os pré-tratamentos: a) ácido sulfúrico PA (98\%) por 60 minutos; b) ácido sulfúrico PA (98\%) por 15 minutos; c) ácido sulfúrico PA (98\%) por 5 minutos; d) escarificação mecânica com lixa no 80 e e) controle. No terceiro experimento os pré-tratamentos foram: a) ácido sulfúrico PA (98\%) por 1 minuto; b) ácido sulfúrico PA (98\%) por 3 minutos; c) ácido sulfúrico PA $(98 \%)$ por 5 minutos; d) escarificação com lixa ${ }^{\circ}$ 80 ; e) imersão em água a $100^{\circ} \mathrm{C}$ por $15 \mathrm{~min}$. e f) controle. Nos dois primeiros experimentos houve baixa percentagem de germinação, com maior média de $25 \%$. No terceiro experimento a germinação foi maior nos tratamentos com ácido sulfúrico (40\% a 70\%). As sementes de $B$. balansae apresentam dormência tegumentar que é superada com a imersão em ácido sulfúrico PA (98\%) por 1 minuto.
\end{abstract}

Palavras-chave: Bromelia balansae, planta medicinal, caraguatá, germinação, cerrado.

\section{ABSTRACT \\ Overcoming seed dormancy of Bromelia balansae (Bromeliaceae)}

The effects of temperature and substrates and different methods to overcome dormancy of Bromelia balansae (caraguatá) seeds were evaluated. The fruits were collected on Chapada dos Guimarães, Mato Grosso State, Brazil. The experimental design was completely randomized with five replications of 50 seeds for each sample. On the first experiment the seeds were submitted to six treatments: a) $25^{\circ} \mathrm{C}$ and over the paper, b) $30^{\circ} \mathrm{C}$ and over the paper, c) $25^{\circ} \mathrm{C}$ and between papers, d) $35^{\circ} \mathrm{C}$ and between papers, e) alternating $25 / 30^{\circ} \mathrm{C}$ and over the paper f) alternating $25 / 30^{\circ} \mathrm{C}$ and between papers. On the second experiment we evaluated a) immersion in concentrated sulfuric acid PA (98\%) during 60 minutes, b) immersion in concentrated sulfuric acid PA (98\%) during 15 minutes, c) immersion in concentrated sulfuric acid PA (98\%) during 5 minutes, d) mechanical scarification with $\mathrm{n}^{\circ} 80$ sandpaper, e) control. On the third experiment we evaluated a) sulfuric acid PA (98\%) for 1 minute; b) sulfuric acid PA (98\%) for 3 minutes; c) sulfuric acid PA (98\%) for 5 minutes; d) mechanical scarification with $n^{\circ} 80$ sandpaper, e) immersion in water at $100^{\circ} \mathrm{C}$ and f) control. On the two first experiments the seed germination was low. On the third experiment the seed germination was higher in the treatments with sulfuric acid ( $40 \%$ to $70 \%)$. The seeds of B. balansae present seedcoat dormancy that is overcome with the sulfuric acid immersion $100 \%$ for 1 minute.

Keywords: Bromelia balansae, medicinal plant, caraguatá, germination, savannah.

(Recebido para publicação em 6 de maio de 2010; aceito em 28 de setembro de 2011) (Received on May 6, 2010; accepted on September 28, 2011)

$B$ romelia é um dos gêneros mais diversos dentro de Bromelioideae e inclui 56 espécies (Luther, 2006) que se distribuem da região central do México até a Bacia do Prata, na Argentina. Dois centros de diversidade podem ser reconhecidos para o gênero, o primeiro na América Central, estendendo-se aos Andes; e o segundo no Escudo Brasileiro, principalmente no Domínio do Cerrado (Benzing, 2000).

No cerrado é freqüente a Bromelia balansae Mez., conhecida como ca- raguatá. Espécie com vários usos e funções junto aos povos tradicionais e ecossistemas, dentre eles, a extração de fibras, a alimentação humana e animal (aves, quati e outros mamíferos), uso fitoterapêutico em ferimentos e garganta inflamados, xarope e expectorante. É apontada como espécie útil na formação de sistemas agroflorestais na grande área do cerrado e na região sul e sudeste (Pott et al., 2004).

O cerrado contém uma flora medicinal riquíssima, com cerca de 700 espécies utilizadas na medicina popular, porém a grande maioria destas espécies requer estudos básicos que viabilizem sua conservação (Vieira \& Alves, 2003) e os aspectos agronômicos de várias espécies são ainda desconhecidos. Labouriau (1963, 1966) enfatizou a necessidade de se estudar a germinação, a viabilidade e os mecanismos de dispersão de sementes de espécies do cerrado. Albuquerque et al. (2003) apresentaram uma revisão dos estudos conduzidos com germinação de espécies 
medicinais do cerrado em Mato Grosso, mas não constam informações sobre Bromelia balansae.

Existem sementes que, devido a características físicas e químicas do tegumento, apresentam estrutura e consistência compactas e impermeáveis à água e gases e inibições mecânica e química da germinação. Tal fenômeno constitui fator limitante à propagação da espécie, ocorrendo principalmente em leguminosas e outras famílias que possuem sementes com tegumento duro e impermeável (Bewley \& Black, 1994).

Rolston (1978) verificou que das 260 espécies de leguminosas examinadas, cerca de $85 \%$ apresentavam sementes com tegumento total ou parcialmente impermeável à água. Nesse tipo de dormência, o procedimento em laboratório é a remoção do tegumento ou a escarificação química ou mecânica. Em condições naturais, a escarificação pode ocorrer pelo aquecimento úmido ou seco do solo, ou por temperaturas alternadas, o que permitiria a água chegar ao interior da semente. Esse processo pode ocorrer também pela ação de ácidos, quando da ingestão das sementes por animais dispersores, além da ação dos microorganismos presentes no solo (Vazquez-Yanes \& Orozco-Segovia, 1993).

Em B. balansae o papel de animais dispersores parece ser importante na superação da dormência, pois em estudo conduzido na serra do Japi-SP, Nakano-Oliveira et al. (2004) verificaram que as sementes que passaram pelo trato digestivo do quati (Nasua nasua) apresentaram uma taxa de germinação significativamente maior que as retiradas diretamente do fruto.

Diante das considerações acima, este trabalho teve o objetivo de verificar o efeito da temperatura, tipo de substrato e de pré-tratamentos germinativos para superar a dormência de Bromelia balansae.

\section{MATERIAL E MÉTODOS}

Os frutos maduros de $B$. balansae foram coletados em dezembro de 2004 em Chapada dos Guimarães-MT, e foram acondicionados em sacolas de polietileno abertas em ambiente com ar refrigerado $\left(24^{\circ} \mathrm{C}\right)$ durante o dia e à noite em temperatura ambiente, durante cinco dias. As sementes foram então extraídas manualmente dos frutos sadios, lavadas em água corrente, colocadas sobre folhas de papel mata borrão, e postas a secar em local protegido da luz solar direta, em temperatura ambiente (25$30^{\circ} \mathrm{C}$ ). Após a secagem foram colocadas em sacola de papel pardo e armazenadas em câmara climatizada $\left(16 \pm 3^{\circ} \mathrm{C}\right.$ e $U R=60 \pm 10 \%$ ). O teor de água foi determinado, antes da realização dos experimentos, pelo método da estufa a $105 \pm 3^{\circ} \mathrm{C}$, com duas subamostras de cinco gramas de sementes, por 24 horas e o peso de mil sementes foi obtido com oito repetições de 100 sementes segundo as Regras para Análise de Sementes, (Brasil, 2009).

Foram conduzidos três experimentos no Laboratório de Sementes da Universidade Federal de Mato Grosso. No final dos experimentos, realizou-se no Laboratório de Fitopatologia a análise sanitária das sementes ainda restantes, utilizando o "blotter test", conforme Neergaard (1977) e a determinação das sementes deterioradas de acordo com Brasil, (2009).

Experimento I: conduzido de janeiro a abril de 2005 . As sementes foram colocadas para germinar utilizando os substratos sobre papel e entre papel nas temperaturas de $25^{\circ} \mathrm{C}, 30^{\circ} \mathrm{C}$ e temperatura alternada $25 / 30^{\circ} \mathrm{C}$, no esquema fatorial $2 \times 3$.

O papel mata borrão foi previamente submetido à autoclave por uma hora e colocado em caixas de plástico transparente tipo "gerbox" (11,5 x 11,5 x $3,5 \mathrm{~cm}$ ), que foram desinfetadas com álcool $70 \%$ e esterilizadas em autoclave à temperatura de $120^{\circ} \mathrm{C}$ por duas vezes, por um período de 20 minutos. Após a semeadura as caixas gerbox foram cobertas com filme de PVC transparente "insulfilme" e mantidas em câmara de germinação tipo BOD com fotoperíodo de 8 horas de luz e 16 de escuro.

Diariamente, durante 110 dias foi realizada a contagem de germinação, tendo como critério a protrusão da raiz primária $\geq 2 \mathrm{~mm}$. Posteriormente, foram calculados a porcentagem de germinação e o índice de velocidade de germinação segundo Maguire (1962).

Experimento II: conduzido em fevereiro de 2005. As sementes receberam os tratamentos pré-germinativos: a) ácido sulfúrico PA (98\%) durante 60 minutos; b) ácido sulfúrico PA (98\%) durante $15 \mathrm{~min}$; c) ácido sulfúrico PA (98\%) durante 5 minutos; d) escarificação mecânica com lixa ${ }^{\circ} 80$; e) controle (sem pré-tratamento). A semeadura foi feita sobre papel, conforme descrita anteriormente e as sementes mantidas em câmara de germinação do tipo BOD com temperatura controlada em $30^{\circ} \mathrm{C}$ e as avaliações feitas idênticas ao primeiro experimento.

Experimento III: conduzido em fevereiro de 2005, em função da alta incidência de fungos verificada no segundo experimento. As sementes receberam os tratamentos: a) imersão em ácido sulfúrico PA (98\%) por 1 minuto; b) imersão em ácido sulfúrico PA (98\%) por 3 minutos; c) imersão em ácido sulfúrico PA (98\%) por 5 minutos; d) escarificação com lixa $n^{\circ} 80$; e) choque térmico com imersão em água a $100^{\circ} \mathrm{C}$ por 5 min. e posteriormente em água destilada a $20^{\circ} \mathrm{C}$ por $5 \mathrm{~min}$.; f) controle (sem pré-tratamento).

O substrato utilizado foi papel mata borrão em caixas de plástico transparentes tipo "gerbox" (11,5 x 11,5 x 3,5 $\mathrm{cm})$ umedecido com água destilada mantidas em câmara de germinação tipo BOD com temperatura controlada em $30^{\circ} \mathrm{C}$, com fotoperíodo de 8 horas de luz e 16 de escuro. Para eliminar as fontes infectantes foram utilizados formol a 2,5\%, hipoclorito de sódio e álcool a 70\%, na câmara de germinação, bancada de trabalho, gerbox e demais instrumentos utilizados. A lixa para a escarificação foi esterilizada em estufa a $100^{\circ} \mathrm{C}$ por 1 hora.

O delineamento experimental utilizado foi inteiramente casualizado para todos os experimentos, com cinco repetições de 50 sementes. Os dados foram submetidos à analise de variância e as médias comparadas pelo teste Scott-Knott, em nível de 5\% de probabilidade (Ribeiro Junior \& Melo, 2009).

\section{RESULTADOS E DISCUSSÃO}

O teor de água nas sementes foi de 
Tabela 1. Germinação, deterioração e índice de velocidade de germinação (IVG) de $B$. balansae em diferentes substratos e temperaturas; experimento I (seed germination, decay and germination speed index of B. balansae in different substrates and temperatures; experiment I). Cuiabá, UFMT, 2005.

\begin{tabular}{|c|c|c|c|c|c|c|}
\hline \multirow{2}{*}{$\begin{array}{l}\text { Temperatura } \\
\left({ }^{\circ} \mathrm{C}\right)\end{array}$} & \multicolumn{2}{|c|}{ Germinação (\%) } & \multicolumn{2}{|c|}{ Deterioração (\%) } & \multicolumn{2}{|c|}{ IVG } \\
\hline & entre papel & sobre papel & entre papel & sobre papel & entre papel & sobre papel \\
\hline 25 & $25 \mathrm{a}$ & $23 \mathrm{a}$ & $40 \mathrm{a}$ & $40 \mathrm{a}$ & 0,315 a & 0,284 a \\
\hline 30 & $13 \mathrm{~b}$ & $23 \mathrm{a}$ & $60 \mathrm{a}$ & $36 \mathrm{~b}$ & 0,249 a & 0,165 a \\
\hline $25 / 30$ & $8 \mathrm{~b}$ & $11 \mathrm{a}$ & $25 \mathrm{~b}$ & $36 \mathrm{~b}$ & 0,480 a & $0,074 \mathrm{~b}$ \\
\hline
\end{tabular}

Médias na vertical, seguidas por mesma letra não diferem estaticamente entre si, pelo teste Scott-Knott a 5\% de probabilidade (means followed by the same letter in column are not different by the Scott-Knott test at 5\%).

Tabela 2. Germinação, deterioração e índice de velocidade de germinação (IVG) de $B$. balansae em diversos pré-tratamentos para a superação da dormência; experimento III (seed germination, decay and germination speed index of B. balansae in different treatments for overcoming seed dormancy; experiment III). Cuiabá, UFMT, 2005.

\begin{tabular}{lccc}
\hline Tratamentos & $\begin{array}{c}\text { Germinação } \\
(\mathbf{( \% )}\end{array}$ & $\begin{array}{c}\text { Deterioração } \\
(\mathbf{( \% )}\end{array}$ & IVG \\
\hline ácido sulfúrico por 1 minuto & $70 \mathrm{a}$ & $5,8 \mathrm{~b}$ & $0,17 \mathrm{a}$ \\
ácido sulfúrico por 3 minutos & $56 \mathrm{~b}$ & $5,6 \mathrm{~b}$ & $0,13 \mathrm{~b}$ \\
ácido sulfúrico por 5 minutos & $40 \mathrm{c}$ & $11,8 \mathrm{a}$ & $0,09 \mathrm{c}$ \\
lixa $\mathrm{n}^{\mathrm{o}} 80$ & $10 \mathrm{~d}$ & $10,0 \mathrm{a}$ & $0,02 \mathrm{~d}$ \\
choque térmico (água a $\left.100^{\circ} \mathrm{C}\right)$ & $13 \mathrm{~d}$ & $15,0 \mathrm{c}$ & $0,02 \mathrm{~d}$ \\
controle & - & - & - \\
\hline
\end{tabular}

Médias na vertical, seguidas por mesma letra não diferem estaticamente entre si, pelo teste Scott-Knott a $5 \%$ de probabilidade (means followed by the same letter in column are not different by the Scott-Knott test at 5\%).

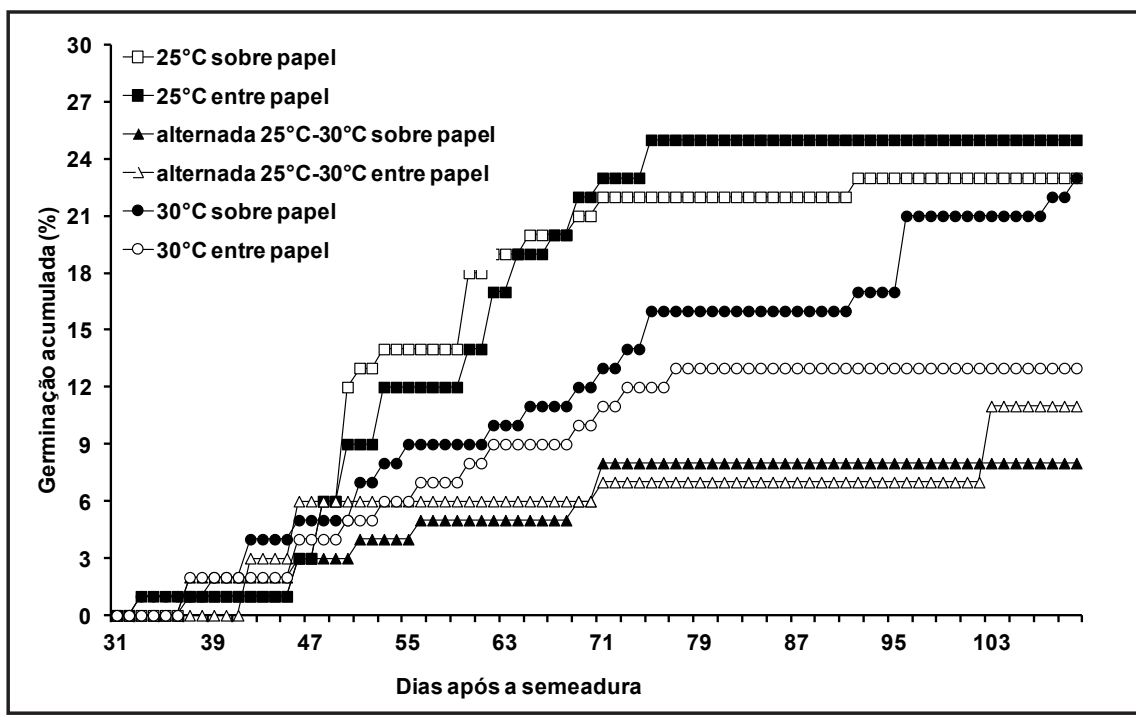

Figura 1. Germinação de $B$. balansae em diferentes substratos e temperaturas; experimento I (seed germination of B. balansae in different substrates and temperatures; experiment I). Cuiabá, UFMT, 2005.

$12,8 \%$, o peso de mil sementes foi 23,5 g, o desvio padrão de 0,05 e o coeficiente de variação foi 1,95 para as amostras analisadas em janeiro de 2005.

$\mathrm{Na}$ Tabela 1 encontram-se a per- centagem de sementes germinadas e deterioradas e o índice de velocidade de germinação de $B$. balansae em diferentes substratos e temperaturas.

As sementes colocadas entre papel e em temperatura alternada apresentaram a menor germinação (8\%). Nos demais tratamentos a germinação foi maior, entretanto os valores foram baixos tanto para esta como para a velocidade de germinação. Nesse período de observação a percentagem de sementes deterioradas foi elevada chegando a $60 \%$ no final do experimento. Estes resultados indicam algum processo de dormência dessas sementes, pois o teste de tetrazólio realizado de acordo com Añez et al. (2007), comprovou que as sementes estavam vivas. Reforça esta hipótese o trabalho de Nakano-Oliveira et al. (2004) que, ao analisarem sementes de $B$. balansae que passaram pelo trato digestivo do quati (Nasua nasua), observaram uma taxa de germinação significativamente maior que aquela observada em sementes retiradas diretamente do fruto e aquelas que passaram pelo trato digestivo do cachorro-do-mato (Cerdocyon thous) apresentaram maior velocidade de germinação.

Por outro lado, a dormência não é relatada em espécies da família. Pereira et al. (2008) estudaram a germinação de seis espécies de Bromeliaceae pertencentes a outros gêneros e verificaram a ausência de dormência com tempo médio de germinação variando de 4 a 15 dias. Pereira (1988) estudou 58 espécies da mesma família e verificou que $73 \%$ germinaram entre quatro e sete dias após a semeadura, contrastando com o comportamento germinativo das sementes observado no presente estudo (Figura 1), em que o início da germinação ocorreu aos 33 dias e prolongou-se até 110 dias após a semeadura, de forma descontínua, sugerindo o fenômeno da dormência.

A dormência de sementes é de 


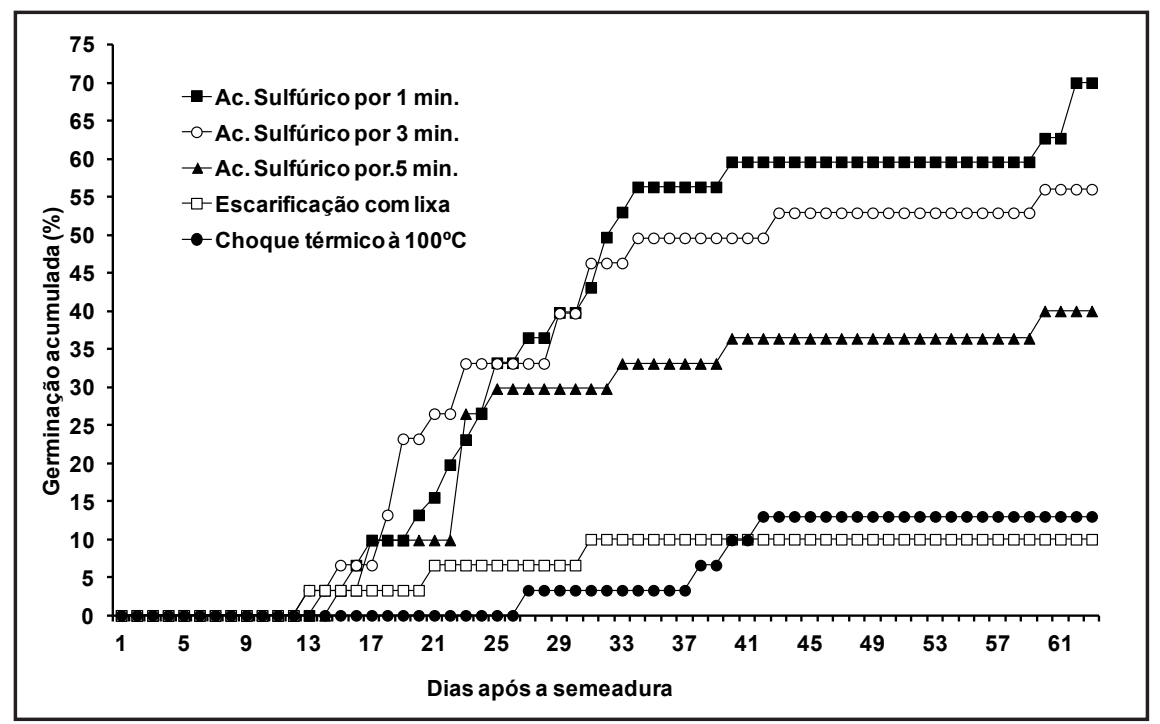

Figura 2. Germinação de B. balansae em diferentes pré-tratamentos para a superação da dormência; experimento III (seed germination of B. balansae in different treatments for overcoming seed dormancy; experiment III). Cuiabá, UFMT, 2005.

fundamental importância para a perpetuação e o estabelecimento de muitas espécies vegetais nos mais variados ambientes (Zaidan \& Barbedo, 2004). Entretanto, para a produção de mudas de bromélias em viveiros, visando sua reintrodução em ambientes degradados ou para comercialização, a ausência de dormência nas sementes se mostra interessante sobre o aspecto prático, reduzindo o tempo gasto no processo de produção de mudas (Pereira et al., 2008).

Em sementes que apresentam impermeabilidade do tegumento a superação da dormência tem sido obtida com sucesso pela escarificação mecânica com lixa ou pela imersão em ácido sulfúrico, como é o caso de Stryphnodendron adstringens e Stryphnodendron polyphyllum (Martins \& Nakagawa, 2008).

No experimento II, mesmo utilizando pré-tratamentos para a superação da dormência, as sementes não germinaram, com exceção daquelas tratadas com ácido sulfúrico por 5 minutos, que apresentaram $36 \%$ de germinação. A ausência da germinação foi causada principalmente pelo desenvolvimento de diversos microorganismos nas sementes após três dias de instalação do experimento. Os fungos identificados foram Rhizopus spp., Penicillium spp., Aspergillus spp., Periconia spp., com Añez et al. (2007) comprovou que as sementes estavam vivas. Pacheco \& Matos (2009) obtiveram resultados semelhantes em sementes de Apeiba tibourbou, quando aumentaram o tempo de imersão para 5 e 10 minutos, e afirmam que provavelmente, houve ocorrência de danos fisiológicos na estrutura interna da semente, que podem ter atingido o embrião, acarretando a morte da semente.

Alves et al. (2006) observaram que o pré-condicionamento das unidades de dispersão de Zizyphus joazeiro em $\mathrm{H}_{2} \mathrm{SO}_{4}$ concentrado promoveu a germinação, mas a eficiência do tratamento depende do período de imersão, sendo a faixa entre 74 e 115 minutos mais adequada para proporcionar maior porcentagem de emergência na primeira contagem. O ácido sulfúrico, segundo Albuquerque et al. (2003) em sua compilação de dados para condições de teste de germinação de espécies nativas, é indicado para Cochlospermum regium (durante 120 minutos e em temperatura de $25^{\circ} \mathrm{C}$ ), Copaifera langsdorffii (durante 5 minutos e em $25^{\circ} \mathrm{C}$ ) e Bowdichia virgilioides (por 5 e $8 \mathrm{~min} \mathrm{em} 30^{\circ} \mathrm{C}$ ).

Michereff \& Barros (2001) afirmam que o ácido sulfúrico aplicado às sementes de algodão faz com que haja eliminação de numerosos fungos presentes no linter. Mas em $B$. balansae no Experimento III ainda houve o aparecimento de fungos e talvez a imersão em $\mathrm{H}_{2} \mathrm{SO}_{4}$ devesse ser mais prolongada. Entretanto, poderia comprometer a viabilidade da semente, uma vez que longos períodos de exposição causam danos às sementes e redução da germinação (Marcos Filho, 1999). Portanto, encontrar a solução mais adequada depende ainda de mais estudos com esta espécie.

Na Figura 2 verifica-se o comportamento germinativo durante a condução do teste. Vários picos de germinação foram observados caracterizando a dormência. A escarificação com lixa e o choque térmico proporcionaram a estabilização da germinação aos 31 e 42 dias após a semeadura respectivamente, com percentagem final inferior a $15 \%$, sugerindo, portanto, que não são eficientes em superar a dormência e promover a germinação de B. balansae. A partir dos 40 dias após a semeadura as sementes 
tratadas com ácido sulfúrico apresentaram estabilidade na germinação, que se manteve até os 60 dias, quando algumas sementes germinaram. Este fato sugere que o período de observação não foi suficiente para a conclusão do processo germinativo.

A ineficiência da escarificação mecânica com a utilização de materiais abrasivos (lixa) na superação da dormência de sementes de B. balansae, provavelmente, deve-se à realização desse método de forma manual, aliada ao curto período de abrasão de aproximadamente 30 segundos. Mas a escarificação mecânica apresentou bons resultados em outras espécies, como os relatados por Hermansen et al. (2000) em Dimorphandra mollis; Santos et al. (2004) em Sterculia foetida e Rodrigues et al. (2009) que constataram que a escarificação mecânica com lixa foi eficiente para superação da dormência das sementes de Adenanthera pavonina.

A imersão em água quente também foi ineficiente para superar a dormência das sementes de $B$. balansae. O estresse térmico pode ser responsável pelo enfraquecimento do tecido tegumentar e propicia o surgimento de fissuras que permitem a absorção de umidade para desencadear o processo germinativo (Pacheco \& Matos, 2009). Em condições ambientais naturais, como no cerrado matogrossense, essa superação de dormência ocorreria pela prática de abertura de clareiras e o uso do fogo seguido de chuvas, como tem sido observado pelos autores deste trabalho.

$\mathrm{Na}$ utilização de $\mathrm{H}_{2} \mathrm{SO}_{4}$ para superar a dormência de sementes florestais deve-se considerar que a manipulação desse produto químico envolve risco de acidentes, que poderiam resultar em queimaduras, além de originar resíduos poluentes nas águas. Outros aspectos que devem ser avaliados são o elevado custo e a dificuldade de obtenção por viveiristas.

Nas condições em que foram realizados os experimentos conclui-se que as sementes de $B$. balansae apresentam dormência tegumentar. A superação da dormência é alcançada com ácido sulfúrico e nos testes de germinação em laboratório a imersão em $\mathrm{H}_{2} \mathrm{SO}_{4}$ deve ser feita por 1 minuto e as sementes colocadas sobre papel mata borrão na temperatura de $30^{\circ} \mathrm{C}$.

\section{AGRADECIMENTOS}

Ao CNPq pela concessão da Bolsa de Produtividade à primeira autora e à professora Leimi Kobayasti pela identificação dos fungos nas sementes.

\section{REFERÊNCIAS}

ALBUQUERQUE MCF; COELHO MFB; ALBRECTH JMF. 2003. Germinação de sementes de espécies medicinais do Cerrado. In: COELHO MFB; COSTA JUNIOR P; DOMBROSKI JLD. Diversos olhares em etnobiologia, etnoecologia e plantas medicinais. Cuiabá: UNICEN, p.157-181.

ALVES EU; BRUNO RLA; OLIVEIRA AP; ALVES AU; ALVES AU. 2006. Ácido sulfúrico na superação da dormência de unidade de dispersão de juazeiro (Zizyphus joazeiro Mart.). Revista Árvore 30: 187-195.

AÑEZ LMM; COELHO MFB; ALBUQUERQUE MCF; MENDONÇA EAF; DOMBROSKI JLD. 2007. Padronização da metodologia do teste de tetrazólio para sementes de Jatropha elliptica M. Arg. (Euphorbiaceae). Revista Brasileira de Plantas Medicinais 9: 82-88.

BENZING DH. 2000. Bromeliaceae: profile of an adaptive radiation. Cambrigde: University Press, 590p.

BEWLEY JD; BLACK M. 1994. Seeds: physiology of development and germination. 2. ed. New York: Plenum Press, 445p.

BRASIL. Ministério da Agricultura. 2009. Regras para Análise de Sementes. Brasília, Ministério da Agricultura, 399p.

HERMANSEN LA; DURYEA ML; WHITE TL. 2000. Pre-treatments to overcome seed coat dormancy in Dimorphandra mollis. Seed Science and Technology 28: 581-595.

LABOURIAU LG. 1963. Problemas da fisiologia ecológica dos cerrados. In: SIMPÓSIO SOBRE O CERRADO, 1. Anais... São Paulo: EdUSP p. 233-276.

LABOURIAU LG. 1966. Revisão da situação da ecologia vegetal nos cerrados. Anais Academia Brasileira Ciências, 38. (Suplemento sobre o cerrado). p. 3-38.

LUTHER HE. 2006. An alphabetical list of bromeliad binomies. The Bromeliad Society International. 10. ed. Florida: The Marie Selby Botanical Gardens. 116p.

MAGUIRE JD. 1962. Speed of germination-aid in relation to evaluation for seedling emergence vigor. Crop Science 2: 176-177.

MARCOS FILHO J. 1999. Teste e vigor: importância e utilização. In: KRZYZANOWSKI FC; VIEIRA RD; FRANÇA NETO JB (eds). Vigor de sementes: conceito e testes. Londrina: Abrates, p. 1-20.

MARTINS CC; NAKAGAWA J. 2008. Germinação de sementes de Stryphnodendron adstringens (Mart.) Coville de diferentes origens submetidas a tratamentos para superação de dormência. Revista Árvore 32: 1059-1067.

MICHEREFF SJ; BARROS R. (eds). 2001. Proteção de plantas na agricultura sustentável. Recife: UFRPE-Imprensa Universitária, 368p.

NAKANO-OLIVEIRA E; PAULINO-NETO HF; JARDIM MA; MEDEIROS RP; VASCONCELLOS-NETO J. 2004. Eficiência na Dispersão de sementes de gravatá Bromélia balansae por carnívoros onívoros (Carnívora: Mamalia). In: CONGRESSO BRASILEIRO DE ZOOLOGIA, 25. Anais... Brasília: DF/ UNB p. 219-220.

NEERGAARD P. 1977. Seed pathology. London: Mac Millan Press. 1191p.

PACHECO MV; MATOS VP. 2009. Método para superação de dormência tegumentar em sementes de Apeiba tibourbou Aubl. Revista Brasileira de Ciências Agrárias 4:62-66.

PEREIRA AR; PEREIRA TS; RODRIGUES AS; ANDRADE ACS. 2008. Morfologia de sementes e do desenvolvimento pós-seminal de espécies de Bromeliaceae. Acta Botanica Brasílica 22: 1150-1162.

PEREIRA TS. 1988. Bromelioideae (Bromeliaceae): morfologia do desenvolvimento pós-seminal de algumas espécies. Arquivo do Jardim Botânico do Rio de Janeiro 29: 115-154.

POTT A; POTT VJ; SOBRINHO AAB. 2004. Plantas Úteis à Sobrevivência no Pantanal. In: SIMPÓSIO SOBRE RECURSOS NATURAIS E SÓCIO-ECONÔMICOS DO PANTANAL, 4. Corumbá. Disponível em: http://www.cpap. embrapa.br/agencia/simpan/sumario/palestras/ ArnildoPott.PDF\#search $=\% 22$ Plantas $\% 20$ $\%$ C $3 \% 9$ A te is $\% 20 \%$ C $3 \%$ A $0 \% 20$ Sobreviv\%C3\%AAncia $\% 20$ no $\% 20$ Pantanal\%22. Acessado em 12 de janeiro de 2005 .

RIBEIRO JUNIOR JI; MELO ALP. 2009. Guia prático para utilização do SAEG. Viçosa: Editora Independente, 287p.

RODRIGUES APAC; OLIVEIRAAKM; LAURA VA; YAMAMOTO CR; CHERMOUTH KS; FREITAS MH. 2009. Tratamentos para superação da dormência de sementes de Adenanthera pavonina L. Revista Árvore 33: 617-623.

ROLSTON MP. 1978. Water impermeable seed dormancy. The Botanical Review 44: 365-396.

SANTOS TO; MORAIS TGO; MATOS VP. 2004. Escarificação mecânica em sementes de chichá (Sterculia foetida L.). Revista Árvore 28: 1-6.

VAZQUEZ-YANES C; OROZCO-SEGOVIA A. 1993. Patterns of seed longevity and germination in the tropical rainforest. Annual Review of Ecology and Systematics 24: 69-87.

VIEIRA FR; ALVES RBN. 2003. Desafios para a conservação de recursos genéticos de plantas medicinais e aromáticas no Brasil. In: COELHO MFB; COSTA JUNIOR P; DOMBROSKI JLD (org). Diversos olhares em etnobiologia, etnoecologia e plantas Medicinais. CUIABÁ: UNICEN PUBLICAÇÕES. p. 157-181.

ZAIDAN LBP; BARBEDO CJ. 2004. Quebra de dormência em sementes. p. 135-146. In: FERREIRA AG; BORGHETTI F (eds). Germinação: do básico ao aplicado. Porto Alegre, Artmed. 